\section{Variation of vascular ring as a cause of extubation failure}

\author{
IVANČICA ŠKARIĆ • JASMINKA JAKOBOVIĆ • MAJA KARAMAN ILIĆ • \\ KARMEN KONDŽA • IRENA BABIĆ
}

IVANČICA ŠKARIĆ $(\bowtie) \cdot$ JASMINKA JAKOBOVIĆ• MAJA KARAMAN ILIĆ• KARMEN KONDŽA •

IRENA BABIĆ

Children's Hospital Zagreb

Department of anesthesiology, reanimatology and intensive care Klaićeva 16, 10000 Zagreb, Croatia

Phone: 014600221

Fax: 014600169

E-mail: ivancica.skaric1@zg.t-com.hr

\begin{abstract}
We report on an unexpected extubation failure in a two year old boy. In our patient, failure of extubation led to a diagnostic examination. The result of our examination was discovery of a congenital anomaly of the aortic arch and great vessels (vascular ring) with compression of the trachea. The presence of this anomaly in this patient was unknown to us before. A successful surgical procedure eliminated the underlying cause of the persistent extubation failures.
\end{abstract}

Key words: tracheal compression, vascular ring, extubation failure

\section{Introduction}

Compression of the pediatric airway is a relatively common and often unrecognized complication of aortic arch anomalies. Based on autopsy examinations, it is estimated that $3 \%$ of the population has a congenital anomaly of the aortic arch system; however most of these are asymptomatic and remain undiagnosed. (1) Depending on the degree of tracheoesophageal compression, these anomalies may produce symptoms of stridor, chronic cough, upper respiratory tract infections and dysphagia.

The term vascular ring is used loosely to refer to any vascular anomaly causing tracheoesophageal compression. A complete vascular ring is an aortic arch anomaly in which the trachea and esophagus are surrounded completely by vascular structures. Incomplete vascular rings compress the trachea and esophagus with or without ligaments and fibrous bands. Incomplete rings generally cause a lesser degree of compression and present later than complete rings.

\section{Case report}

A two year old boy with severe psychomotor retardation, epilepsy and encephalopathy was admitted to our Pediatric Intensive Care Unit (PICU) with progressive respiratory failure which required mechanical ventilation. The cause of respiratory failure was bilateral pneumonia. He was ventilated for 14 days.

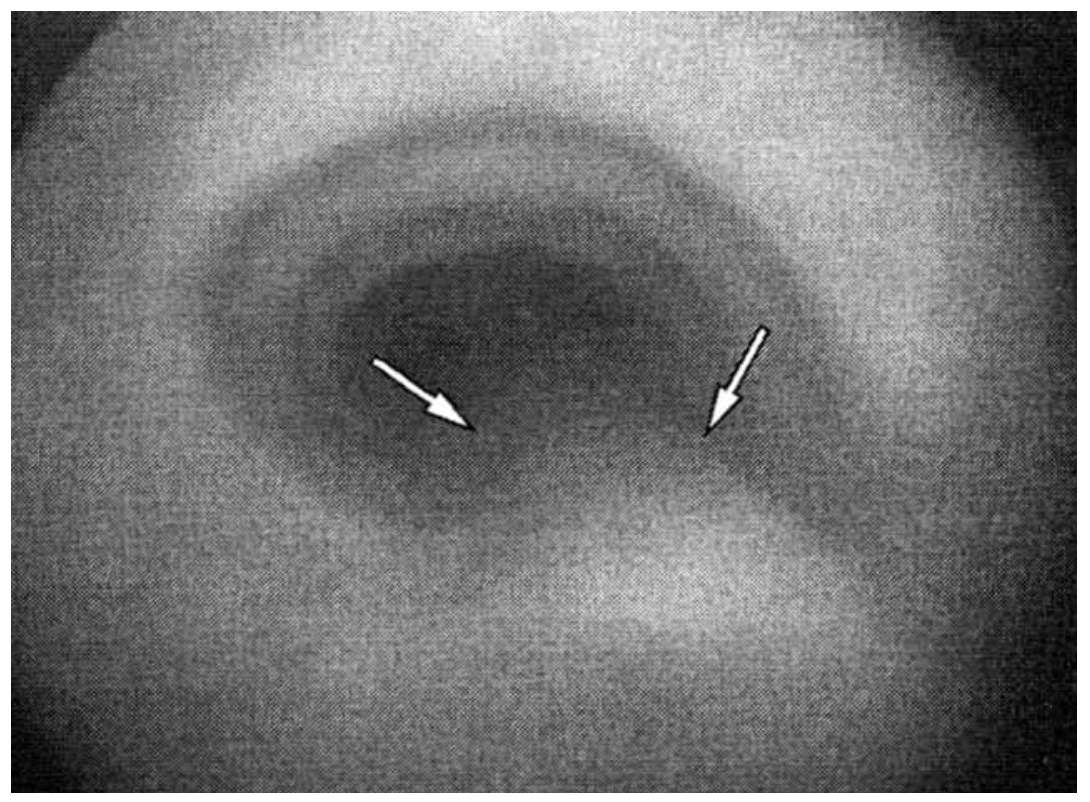

Figure 1. A laryngotracheobronhoscopy (extrinsic compression of the trachea).
Weaning began when the pneumonia had improved, arterial blood gases had normalized, and he became clinically stable. He was extubated after 24 hours of spontaneous breathing through the endotracheal tube, but shortly after extubation respiratory function deteriorated. Severe respiratory disorder manifested with wheezing, sternal and 

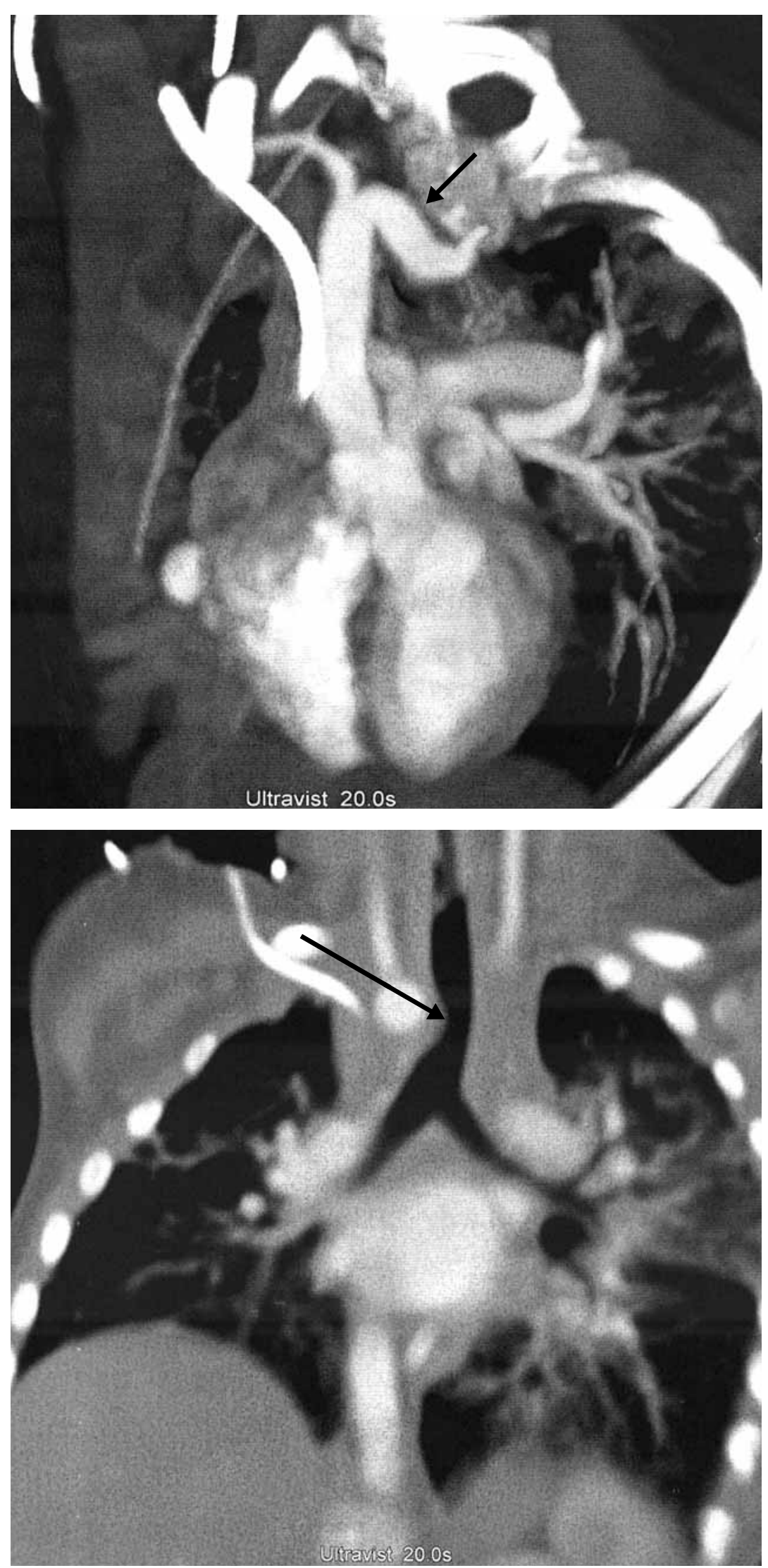

Figure 2. MSCT angiography. The right aortic arch with compression of the trachea. chest retraction, tachydyspnea and tachycardia. Respiratory symptoms did not respond to medication and tracheal intubation was performed again. Two days later, we extubated him again and were once more faced with the same list of complications mentioned above. This prompted us to do an evaluation of why the extubations kept failing. First, a laryngotracheobronhoscopy was done. It showed extrinsic compression of the trachea at two levels (figure 1) and suggested the presence of a vascular ring. The next diagnostic step was to perform a thoracic CT with contrast. It showed atypical positioning of the descending aorta partly in the midline and partly parasagitally on the right and an impression on the dorsal contour of the trachea. The esophagus was sighted in the left parasagital space.

Our radiologist suggested an MRI for better visualization. The MRI showed that a right aortic arch was the cause of the airway compression.

MSCT angiography (figure 2) gave us perfect evaluation of the vascular anomaly. This was in fact a right aortic arch with a variation of its supraaortic branches. The ascending aorta was normally positioned. The first branch was the right carotid artery then the left carotid artery and right subclavian artery, while the left subclavian artery was last, positioned dorsally turning downward and formed the vascular ring around the trachea. The right aortic arch compressed the trachea without a significant reduction of its diameter.

A barium swallow demonstrated asymmetric narrowing of the esophagus consistent with external compression at the level of the aortic arch.

In conclusion, our diagnostic procedure revealed a right aortic arch with aberrant origin of the great arteries. The left subclavian artery arose last from the aortic arch with Kommerell's diverticulum which runs posterior to the esophagus. The ring was completed by the normal course of the left ligament arteriosus between the origin of the left subclavian artery and left pulmonary artery.

The aim of this extensive diagnostic 
investigation was to accurately determine the underlying vascular anatomy before operating. (2)

Resection of the ligamentum arteriosum was performed by left postero-lateral thoracotomy. During the operation, a tracheobronchoscopic evaluation of the trachea was done and the compression was found to be smaller. The boy was successfully extubated two days later and was discharged from hospital without respiratory symptoms.

\section{Discussion}

Vascular rings are a possible cause of respiratory symptoms in infants and young children. (3) Some patients are asymptomatic and discovered only incidentally. Our patient has progressive encephalopathy with epilepsy and psychomotor retardation. He also has swallowing problems and eats only blended food. Before this episode of pneumonia, which was his first case and precipitated his respiratory difficulties, he never had any dangerous respiratory problems. A common cause of pneumonia in children with psychomotor retardation is aspiration of food. However, in this situation, this was not the case. Instead, the pneumonia resulted from the inability to expectorate respiratory secretions. Repeated extubation failure was unexpected so we performed a thorough evaluation of the reasons behind this extubation failure. We thought that a possible reason of extubation failure might have been premature extubation, edema or a lesion of the vocal cords and larynx, tracheomalacia, or an inadequate cough reflex. (4)

A vascular ring was an unexpected result of our examination. Kurachek et al (5) did not report on reasons for extubation failure in PICUs but neither his nor other studies (6) mentioned vascular rings as a reason for extubation failure.

In conclusion we would like to say that extubation failure initiated the diagnostic algorithm which resulted in a diagnosis of vascular ring. Successful surgery eliminated the underlying cause of the persistent extubation failures.

\section{REFERENCES}

1. McLaughlin RB Jr, Wetmore RF, Tavill MA, Gaynor JW, Spray TL. Vascular anomalies Causing Symptomatic Tracheobronhial Compression. Laryngoscope 1999 Feb;109(2 Pt 1):312-9.

2. Harty MP, Kramer SS, Fellows KE. Current concepts in imaging of thoracic vascular abnormalities. Curr Opin Pediatr 2000 Jun;12(3):194202.

3. Bové T, Demanet H, Casimir G, Viart P, Goldstein JP, Deuvaert FE. Tracheobronhial compression of vascular origin. J Cardiovasc Surg 2001 Oct;42(5):663-6.

4. Khan N, Brown A, Venkataraman TS. Predictors of extubation success and failure in mechanically ventilated infants and children. Crit Care Med 2002;24:1568-79.

5. Kurachek SC, Newth CJ, Quasney MW, Rice T, Sachdeva RC, Patel NR, et al. Extubation failure in pediatric intensive care: a multiple-center study of risk factors and outcomes. Crit Care Med 2003 Nov;31(11):2657-64.

6. Edmunds S, Weiss I, Harrison R. Extubation failure in a large pediatric ICU population. Chest 2001 Mar;119(3):897-900. 